\title{
ПРОБЛЕМЫ РАЗВИТИЯ НАУЧНО-ОБРАЗОВАТЕЛЬНОГО КЛАСТЕРА ТОМСКОЙ ОБЛАСТИ В 2011-2019 ГГ.: ДИНАМИКА ИЗМЕНЕНИЙ СТАТИСТИЧЕСКИХ ПОКАЗАТЕЛЕЙ И ЭКСПЕРТНЫХ ОЦЕНОК
}

\author{
Губин Евгений Петрович1, \\ evgenii.p.gubin@tusur.ru \\ Монастырный Евгений Александрович2,1,3, \\ e.monastyrny@gmail.com
}
1 Томский государственный университет систем управления и радиоэлектроники, Россия, г. Томск, пр. Ленина, 40
2 Национальный исследовательский Томский политехнический университет, Россия, 634050, г. Томск, пр. Ленина, 30
3 Томский научный центр СО РАН, Россия, 634055, г. Томск, пр. Академический, 10/4

Губин Евгений Петрович, доцент кафедры управления инновациями Томского государственного университета систем управления и радиоэлектроники.

Монастырный Евгений Александрович, доктор экономических наук, профессор Школы инженерного предпринимательства Национального исследовательского Томского политехнического университета; профессор кафедры управления инновациями Томского государственного университета систем управления и радиоэлектроники; заведующий лабораторией устойчивого развития социально-экономических систем Томского научного центра СО РАН.

Актуальность. Формирование конкурентоспособных территорий и регионов является одной из приоритетных задач государственной политики РФ, в рамках которой остро стоит вопрос об оценке видов экономической деятельности, способных стать драйверами инновационного и социальноэкономического развития регионов. Цель исследования - сравнение динамики изменения объективных статистических показателей процессов деятельности и субъективных экспертных оценок проблем развития научно-образовательного кластера Томской области. Источниками информации являются Росстат, Единая межведомственная информационно-статистическая систем (ЕМИСС), Томскстат, ведомственная и региональная отчетность, экспертные оценки. Методология. Для анализа количественных данных используются подходы описательной статистики: сравнения, отношения, визуализация динамики изменений, статистический анализ; регрессионный анализ. Для анализа качественных данных - приемы выделения из экспертных мнений факторов, характеризующих внешние и внутренние проблемы (угрозы и слабости) исследуемых процессов. Результаты. Разработаны модель-видение взаимодействия основных элементов научно-образовательного регионального кластера, статистические модели, характеризующие процессы развития научнообразовательного кластера Томской области. Рассмотрено финансирование науки в университетах и научно-исследовательских институтах Томской области по данным региональной и ведомственной отчетности (2014-2018). В целом по НОК ТО можно говорить о сформировавшейся в 2014-2018 г2. тенденции сокращения финансирования из всех источников. Объем договоров с российскими хозяйствующими субъектами сокращается, бюджетная поддержкка тоже не увеличивается, новых значимых источников финансирования на обозримую перспективу нет. В статье рассмотрены внутренние затраты на исследования и разработки по секторам деятельности в динамике за 2011-2017 гг. Построены регрессионные зависимости для государственного, предпринимательского секторов и сектора высшего образования. Степень статистической достоверности (значение пара- 
метра $R^{2}$ ) достаточна, чтобы сформулировать гипотезу, что в каждой зависимости проявляется долгосрочный значительный фактор, воздействующий на процессы на протяжении исследуемого периода времени. На основе анализа экспертных мнений (2019 г.) о внутренних и внешних проблемах, ограничивающих процессы развития и препятствующих эффективному взаимодействию организаций кластера, выделены основные факторы, влияющие на исследуемые процессы. Это «Рост государственного финансирования прикладных научных исследований в рамках федеральных целевых программ в интересах государственных корпораций (Роскосмос, Ростех, Росатом и т. п.)», «Непрерывная реформа Российской академии наук, сопровождающаяся снижением государственного финансирования и заказов со стороны хозяйствующих субъектов», «Непрерывная реформа системы образования и университетов, сопровождающаяся снижением государственного финансирования и заказов со стороны хозяйствующих субъектов», «Качество государственного управления и регулирования научными исследованиями», «Качество подготовки специалистов». Говоря о сопоставлении экспертных мнений 2011 и 2019 г2. в целом, необходимо подчеркнуть гораздо более жёсткое и критическое отношение специалистов в 2019 г. к внутренним и внешним проблемам экономики Томской области и России, ограничивающим процессы развития и препятствующим эффективному взаимодействию организаций кластера. Общий вывод. Динамика изменений статистических показателей и экспертных оценок проблем развития научно-образовательного кластера Томской области в 2011-2019 г2. показывает значительное ухудшение экономической ситуаци в стране и нарастание критического отношения специалистов к разработке и реализации политики поддержки научно-технологического развития России.

Ключевые слова: Высокотехнологичные предприятия, университеты, научно-исследовательские институты, прикладная наука, научно-образовательный кластер, статистика, экспертные оценки, моделирование, регрессионный анализ, Томская область.

Формирование конкурентоспособных территорий и регионов является одной из приоритетных задач государственной политики РФ, в рамках которой остро стоит вопрос об оценке видов экономической деятельности, способных стать драйверами инновационного и социально-экономического развития регионов. В мировой практике последние десятилетия особое внимание уделяется анализу развития высокотехнологичных отраслей промышленности, а также высокотехнологичных знаниеемких отраслей сферы услуг на национальном и региональных уровнях [1-3].

Исследование интеграционных процессов различных институтов и организаций в мировой научной литературе проводится по нескольким направлениям.

Во-первых, это разработка и развитие концепции инновационных систем макроуровня - национальных инновационных систем, а также инновационных систем мезоуровня технологических, секторальных и региональных (С. Freeman, B-A. Lundvall, R. Nelson, C. Edquist, D. Dosi, S. Metcalfe, P. Krugman, P. Romer, F. Perroux, M. Porter и др.).

Во-вторых, региональное социально-экономическое пространство исследуется с точки зрения формальных (формализованных) и неформальных (неформализованных) институтов, которые могут оказать существенное влияние на эффективность инновационного процесса и качество сетевого взаимодействия (J.R. Commons, W.J. Samuels, D. North, C. Menar и др.).

В-третьих, исследование отдельных институтов и организаций, играющих существенную роль в инновационных процессах региона и социально-экономическом развитии в целом (B.R. Clark, H. Etzkowitz, L. Leydesdorff, J .Ropke A. Webster и др.).

Применительно к российской действительности целесообразно выделить несколько групп организаций, взаимодействующих в рамках вертикальной (вертикально интегрированные структуры) и горизонтальной (территориальные кластеры) интеграции. Это (1) университеты, позиционирующие себя как исследовательские и предпринимательские, (2) научно-исследовательские организации и академические институты, (3) высокотехнологические предприятия, выполняющие крупные проекты значимых федеральных целевых программ. 
Объектом исследования являются процессы развития научно-образовательного кластера Томской области (НОК ТО). Причем основное внимание уделяется взаимодействию между организациями кластера и проблемам, ограничивающим эффективность этого взаимодействия.

Цель исследования - сравнение динамики изменения объективных статистических показателей процессов деятельности и субъективных экспертных оценок проблем развития научно-образовательного кластера Томской области.

Задачи, которые необходимо решить в рамках этой работы:

1. Сформировать модель-видение взаимодействия основных элементов научнообразовательного регионального кластера.

2. Разработать статистическую модель исследуемых процессов.

3. Определить на основе экспертных оценок совокупность и динамику (2011, 2019 гг.) внутренних и внешних проблем, ограничивающих процессы развития и препятствующих эффективному взаимодействию организаций кластера.

Методология. Для анализа количественных данных в работе используются подходы описательной статистики: сравнения, отношения, визуализация динамики изменений, статистический анализ, регрессионный анализ.

Для анализа качественных данных в работе используются приемы выделения из экспертных мнений факторов, характеризующих внешние и внутренние проблемы (угрозы и слабости) исследуемых процессов.

Моделирование. Изучаемые процессы развиваются в сложном проблемном поле и относятся к классу «мягких» систем, что требует от исследователей использования подходов «мягкого» системного анализа [4-6]. Множественность проблем, неочевидность методов их решения приводят к необходимости построения комплексной модели «мягких» систем как согласованной совокупности моделей разного уровня обобщения и различного целеполагания [7].

Во-первых, разрабатывается структурная модель-видение исследуемого явления с выделением основных действующих лиц (элементов) и взаимодействий между ними.

Во-вторых, строятся статистические модели, отражающие динамику изменений статистических показателей.

В-третьих, на основе анализа всех статистических моделей выделяются наиболее значимые взаимозависимости и строятся линейные регрессии с указанием величины достоверности аппроксимации $\left(\mathrm{R}^{2}\right)$.

Кроме того, проводится сравнение систем факторов, характеризующих внешние и внутренние проблемы (угрозы и слабости) изучаемых процессов, полученных в 2011 г. в ходе исследования основных тенденций развития инновационной системы Томской области (SWOT-анализ) [8] и в ходе полуструктурированных интервью с экспертами высокотехнологичных предприятий, университетов и научно-исследовательских институтов в 2019 г.

Выбор основных источников информации. Источниками информации являются Росстат [9], Единая межведомственная информационно-статистическая систем (ЕМИСС) [10], Томскстат [11], ведомственная отчетность Минобрнауки [12], региональные данные администрации Томской области [13], экспертные оценки.

\section{Результаты исследования}

1. Модель-видение взаимодействия основных элементов научно-образовательного регионального кластера изображена на рис. 1.

Необходимо понимать, что на рисунке отражено только ядро федеральнорегиональной инновационной системы. Каждый из элементов является частью верти- 
кально интегрированных структур. Организации высшего образования входят с систему Минобрнауки РФ, научные организации - в системы Минобрнауки РФ и РАН, крупные и средние высокотехнологичные предприятия - в системы госкорпораций и естественных монополий или тесно сотрудничают с ними. Государство, с одной стороны, задает «правила игры» и обеспечивает текущее функционирование организаций, с другой - стимулирует взаимодействие науки и бизнеса. Одновременно выделенные элементы являются частью национальной и региональной инновационных систем. Сетевые взаимодействия формируются на основе технологических цепочек (производственная кооперация) и рыночного взаимодействия.

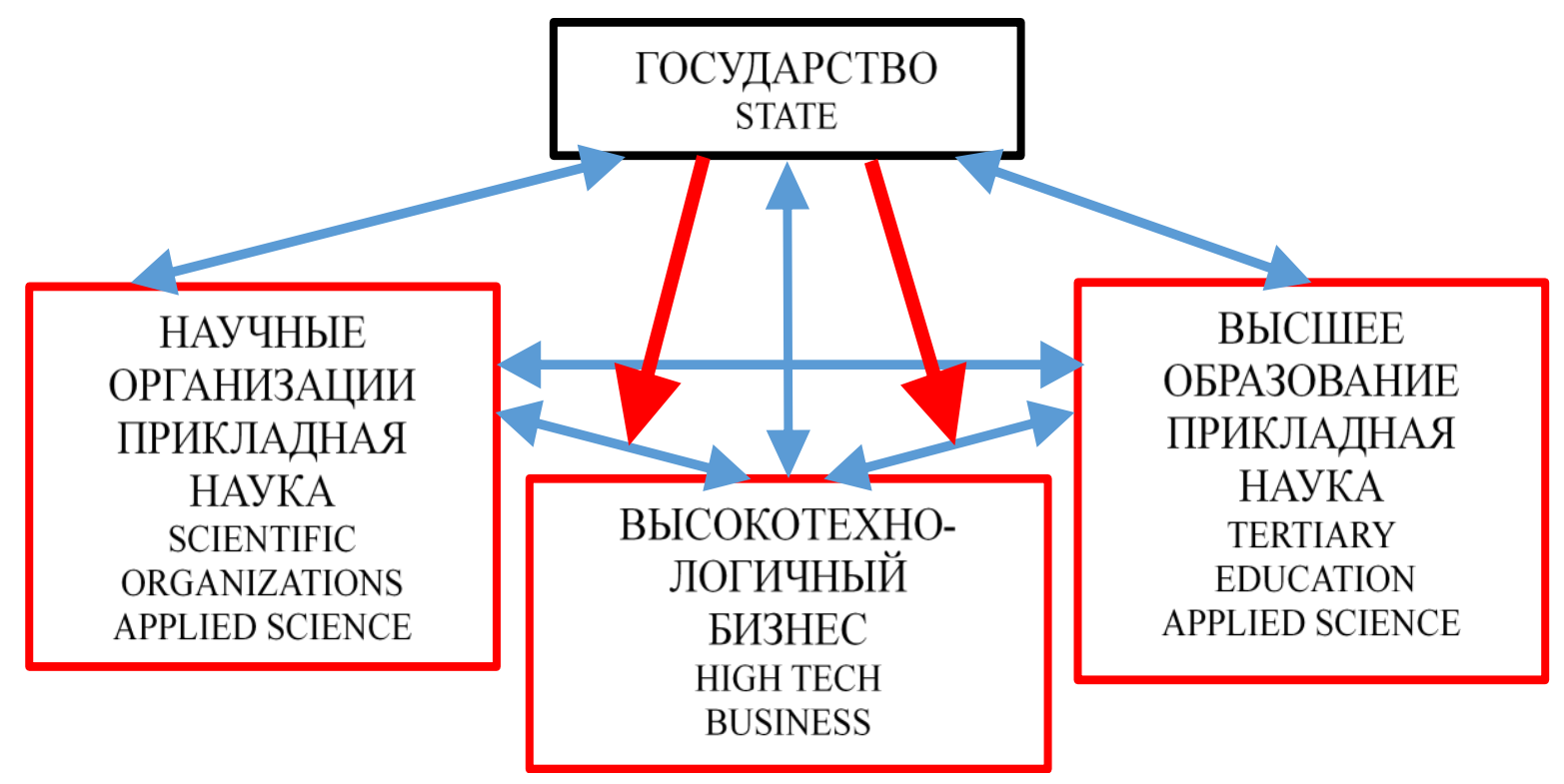

Pис. 1. Модель-видение взаимодействия основных элементов научнообразовательного регионального кластера

Fig. 1. Model-vision of interaction of the main elements of scientific and educational regional cluster

2. Статистические модели, характеризующие процессы развития научнообразовательного кластера Томской области.

Модель в авторском понимании - это целевое структурированное описание объекта анализа. Статистическая модель - это совокупность выявленных на основе данных статистики фактов, раскрывающих в соответствии с целью исследования необходимые характеристики изучаемого явления.

2.1. Динамика показателей отгрузки товаров, оказания услуг в ТО (2005-2018 гг., Росстат $[9,10])$ показана на рис. 2.

Эта статистическая модель динамики процесса развития для отдельных видов экономической деятельности (ВЭД) строится на основе данных Росстата в региональном разрезе.

Инфляция рассчитывается на основе данных Росстата. В результате анализа динамики показателей «Базовый индекс потребительских цен», «Индекс цен производителей по ВЭД. Обрабатывающие производства», «Индекс цен производителей по ВЭД. Производство электрооборудования, электронного и оптического оборудования» в федеральном и региональном разрезах за основной был выбран «Базовый индекс потребительских цен. РФ». Коэффициент инфляции рассчитывается относительно цен 2005 г. 
На рис. 2 приведена динамика показателей отгрузки товаров, оказания услуг в ТО по ВЭД «Обрабатывающие производства», «Научные исследования и разработки» (высокотехнологичные услуги), «Производство электрооборудования, электронного и оптического оборудования» (высокотехнологичное производство). Для лучшего сопоставления изменений проводится нормировка на объемы производства 2005 г. Данные по ВЭД «Производство электрооборудования, электронного и оптического оборудования» ограничены 2016 г., т. к. с 2017 г. действует новый классификатор ВЭД и по данному ВЭД нарушена преемственность статистических рядов.

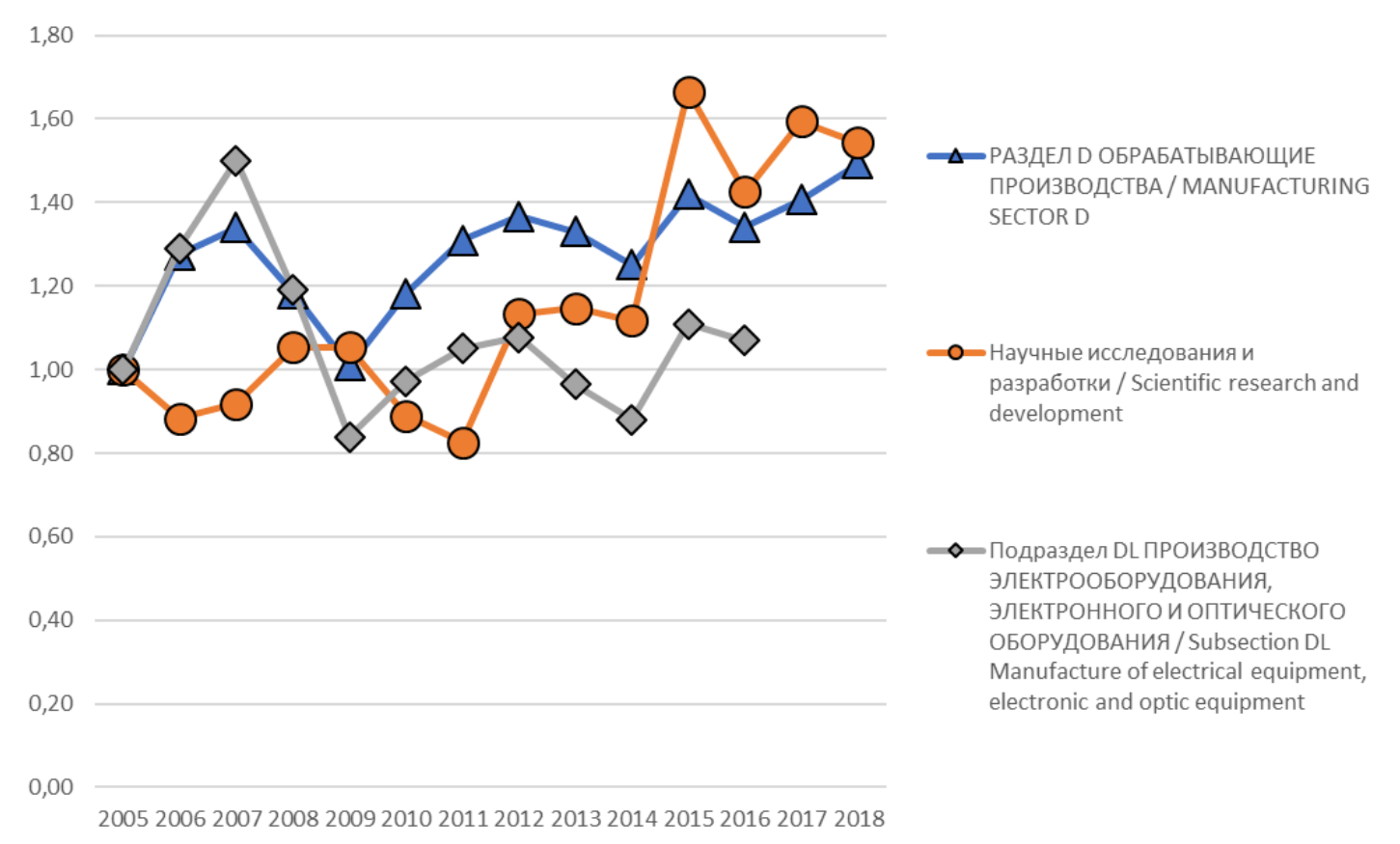

Pис. 2. Динамика показателей отгрузки товаров, оказания услуг в Томской области по ВЭД (2005-2018)

Fig. 2. Dynamics of indicators of goods shipment and services provision in the Tomsk region by types of economic activities (2005-2018)

Данные по динамике производства показывают несколько периодов развития: значительный рост 2005-2007 гг., кризис 2008-2009 гг., послекризисный подъем 2010-2012 гг., стагнацию и неустойчивый рост 2013-2018 гг. Динамика производства по ВЭД «Научные исследования и разработки» несколько другая. Колебания показателей «сдвинуты» примерно на два года.

Понимание динамики изменений необходимо для корректной интерпретации экспертных мнений, т. к. они формируются примерно за 5-7 лет.

2.2. Финансирование науки в университетах и научно-исследовательских институтах Томской области (2014-2018).

Для оценки динамики финансирования науки в университетах и научноисследовательских институтах Томской области используются данные региональной отчетности (Основные результаты деятельности научно-образовательного комплекса Томской области в 2016-2018 гг.) [13]. Все объемы финансирования приведены в ценах 2014 г. (рис. 3, 4).

Региональная отчетность не является обязательной для университетов и НИИ. Кроме того, перечень запрашиваемых показателей часто изменяется, а их формулировки не всегда совпадают со стандартными статистическими терминами. Но несмотря на 
все недостатки, этот источник информации дает большую детализацию данных о развитии НОК ТО. В частности, данные о средствах, получаемых в рамках ФЦП «Исследования и разработки по приоритетным направлениям развития научнотехнологического комплекса России на 2014-2020 годы» (ФЦП «Исследования и разработки») и постановления Правительства № 218 «О мерах государственной поддержки развития кооперации российских высших учебных заведений и организаций, реализующих комплексные проекты по созданию высокотехнологичного производства» (ПП № 218), из других источников труднодоступны.

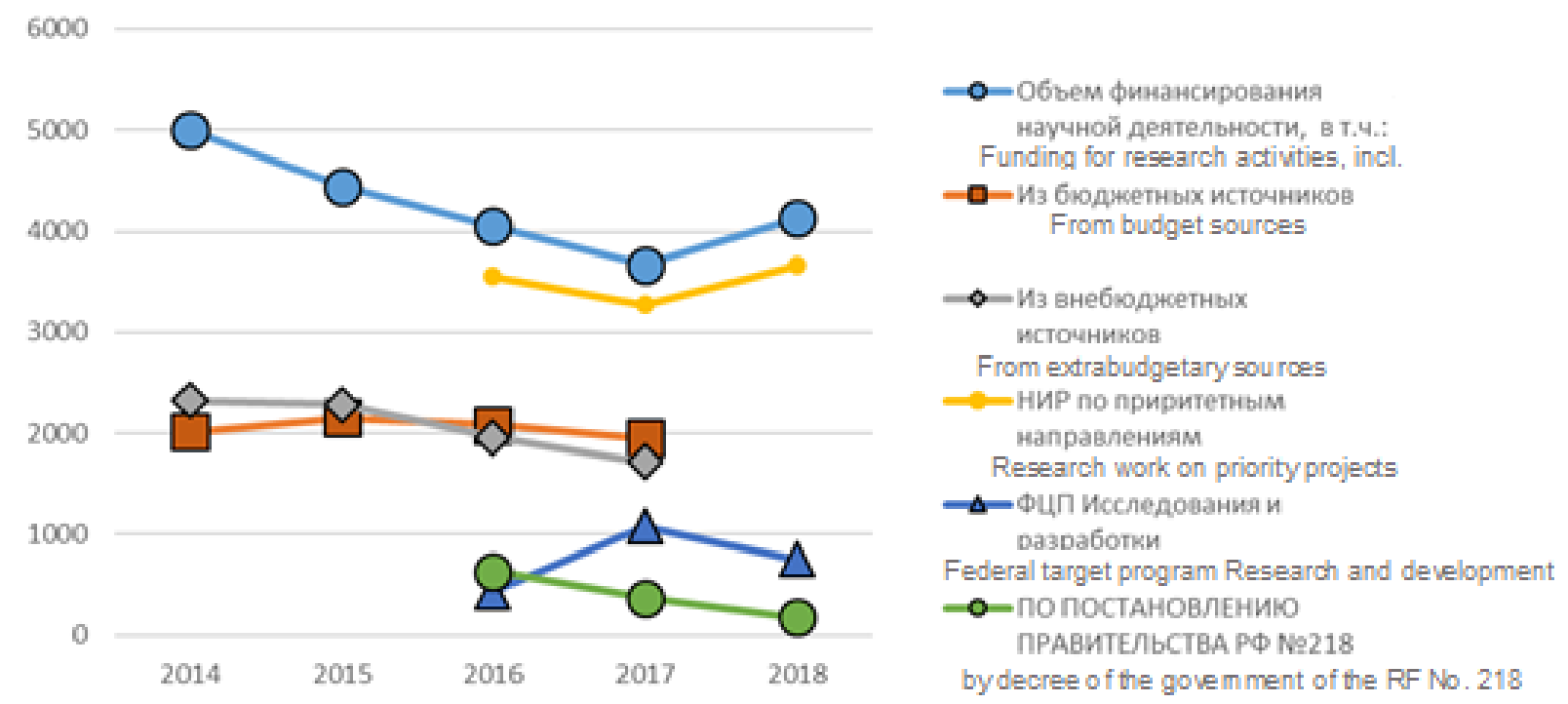

Puc. 3. Финансирование науки в университетах Томской области (2014-2018), млн р. Fig. 3. Financing of science in the universities of the Tomsk region (2014-2018), million rubles
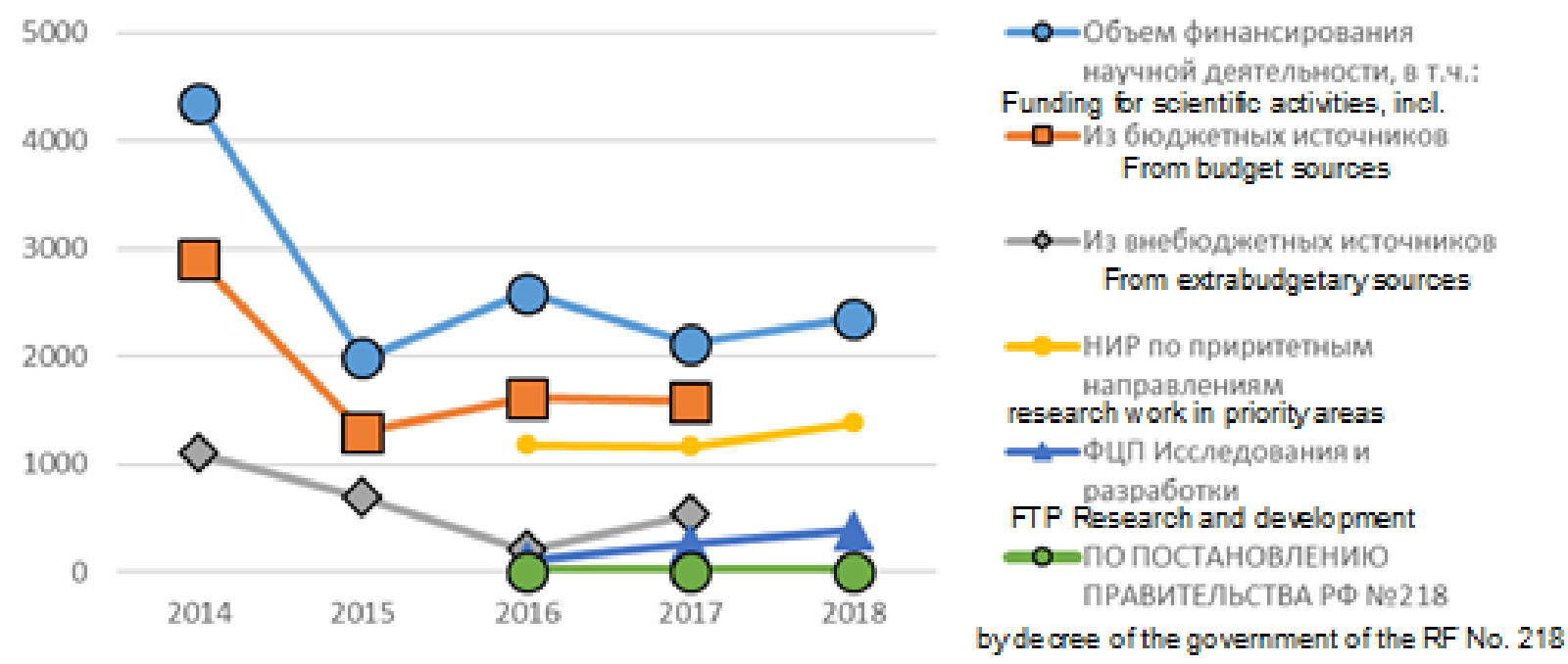

Puc. 4. Финансирование науки в научно-исследовательских институтах Томской области (2014-2018)

Fig. 4. Financing of science in research institutes of Tomsk region (2014-2018)

Приведенная на рис. 3, 4 информация показывает, что для университетов большое значение имеют средства, поступающие из внебюджетных источников (от 47 до $52 \%$ от общего финансирования науки за указанный период), в рамках ФЦП «Исследования 
и разработки» и ПП № 218 (до 40 \% от общего финансирования науки в 2017 г.). Но эти источники показывают тенденцию к уменьшению.

Сложная ситуация с финансированием науки складывается в научноисследовательских институтах региона. Кратное сокращение бюджетного финансирования (в 2,5 раза в 2014, 2015 гг.) сопровождалось значительным падением финансирования из внебюджетных источников. Причем в 2016 г. оно уменьшилось по сравнению с 2014 г. в 5 раз. Формирующийся источник ФЦП «Исследования и разработки» не компенсирует этого падения.

В целом по НОК ТО можно говорить о сформировавшейся в 2014-2018 гг. тенденции сокращения финансирования из всех значимых источников. Неофициальные данные по отдельным университетам и НИИ подтверждают сохранение этой тенденции в 2019 г. и с большой долей вероятности ее продолжение в 2020 г.

Ведомственная отчетность Минобрнауки по Томской области дает примерно те же самые тенденции (в ценах 2013 г.), что и региональная отчетность (рис. 5). Удивление вызывает рост бюджетного (за счет источников Минобрнауки) финансирования в 2014-2015 гг., тогда как региональная отчетность показывает его падение. Объем договоров с российскими хозяйствующими субъектами сокращается, бюджетная поддержка тоже не увеличивается, новых значимых источников финансирования на обозримую перспективу нет.

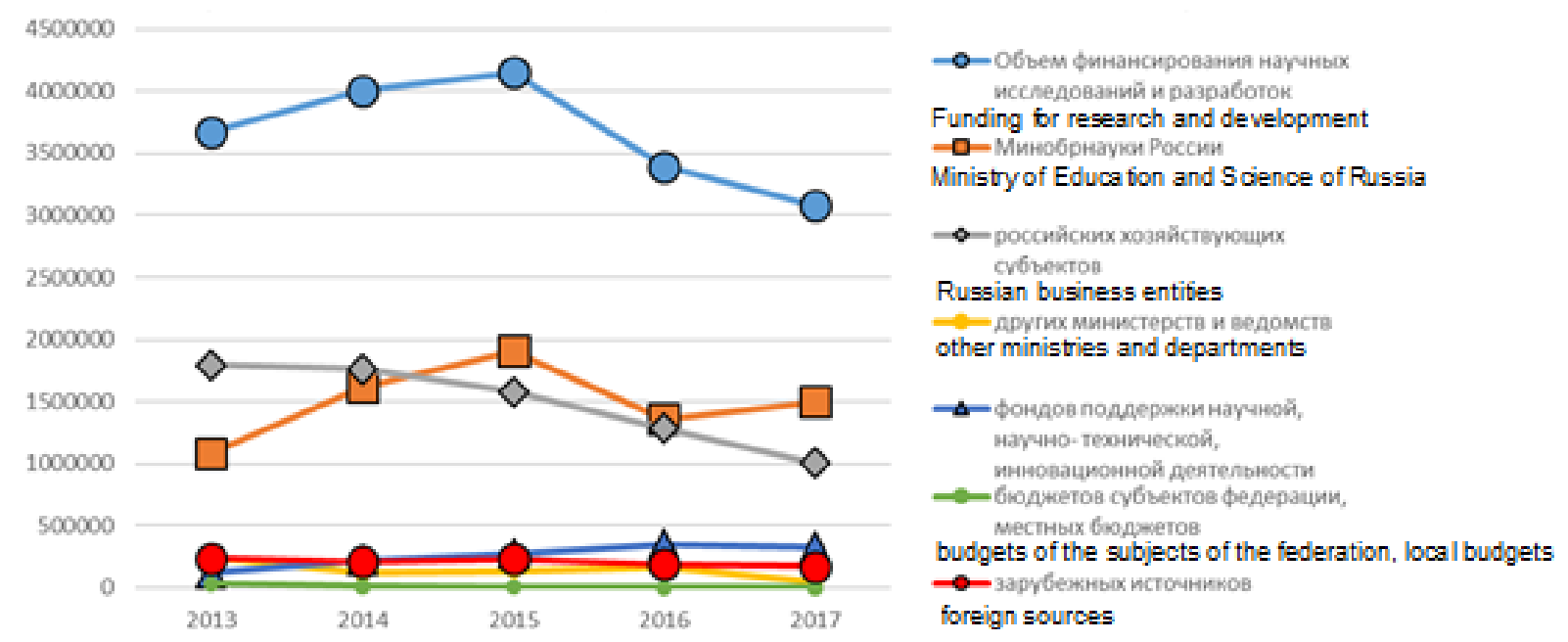

Puc. 5. Финансирование научных исследований и разработок в вузах и научных организациях Минобрнауки. Томская область (2013-2017), тыс. p.

Fig. 5. Financing of research and development in universities and scientific organizations of the Ministry of Education and Science. Tomsk region (2013-2017)

2.3. Внутренние затраты на исследования и разработки по секторам деятельности (2011-2017).

Мозаика статистической модели исследуемого явления, складывающаяся из различных источников, показывает неустойчивое развитие высокотехнологичных секторов экономики (рис. 2) и сокращение финансирования науки в университетах и научноисследовательских институтах (рис. 3-5) научно-образовательного кластера Томской области. Но ни одна из выявленных тенденций динамики показателей не описывается регрессионной зависимостью с приемлемой точностью. Поэтому был предпринят поиск индикаторов, динамика изменений которых может быть аппроксимирована линейной регрессией. 
В результате на основе данных Томскстата [11] (Статистические ежегодники. Томская область. 2015-2018 гг.) была рассмотрена динамика изменения доли внутренних затрат на исследования и разработки по секторам деятельности (2011-2017).

На рис. 6 приведена доля внутренних затрат на исследования и разработки по секторам деятельности - государственному, предпринимательскому и высшего образования.

Государственный сектор науки - это в первую очередь научно-исследовательские институты, финансируемые государством.

Предпринимательский сектор - это в первую очередь крупные высокотехнологичные предприятия в виде акционерных обществ.

Сектор высшего образования - это университеты, в основном финансируемые государством.

Линейная регрессия для предпринимательского сектора имеет вид

$$
\mathbf{y}=\mathbf{0 , 0 3 9 4 x}+0,2607 ; R^{2}=0,8891 \text {. }
$$

Линейная регрессия для сектора высшего образования имеет вид

$$
\mathbf{y}=-\mathbf{0 , 0 1 7 8 x}+\mathbf{0 , 4 2 8 2} ; \mathbf{R}^{\mathbf{2}}=\mathbf{0 , 7 3 5 3}
$$

Линейная регрессия для государственного сектора имеет вид

$$
\mathbf{y}=-0,0215 x+0,3099 ; R^{2}=0,9493 \text {. }
$$

Степень статистической достоверности (значение параметра $\mathrm{R}^{2}$ ) достаточна, чтобы сформулировать гипотезу, что в каждой зависимости проявляется долгосрочный значительный фактор, воздействующий на процессы на протяжении исследуемого периода времени.

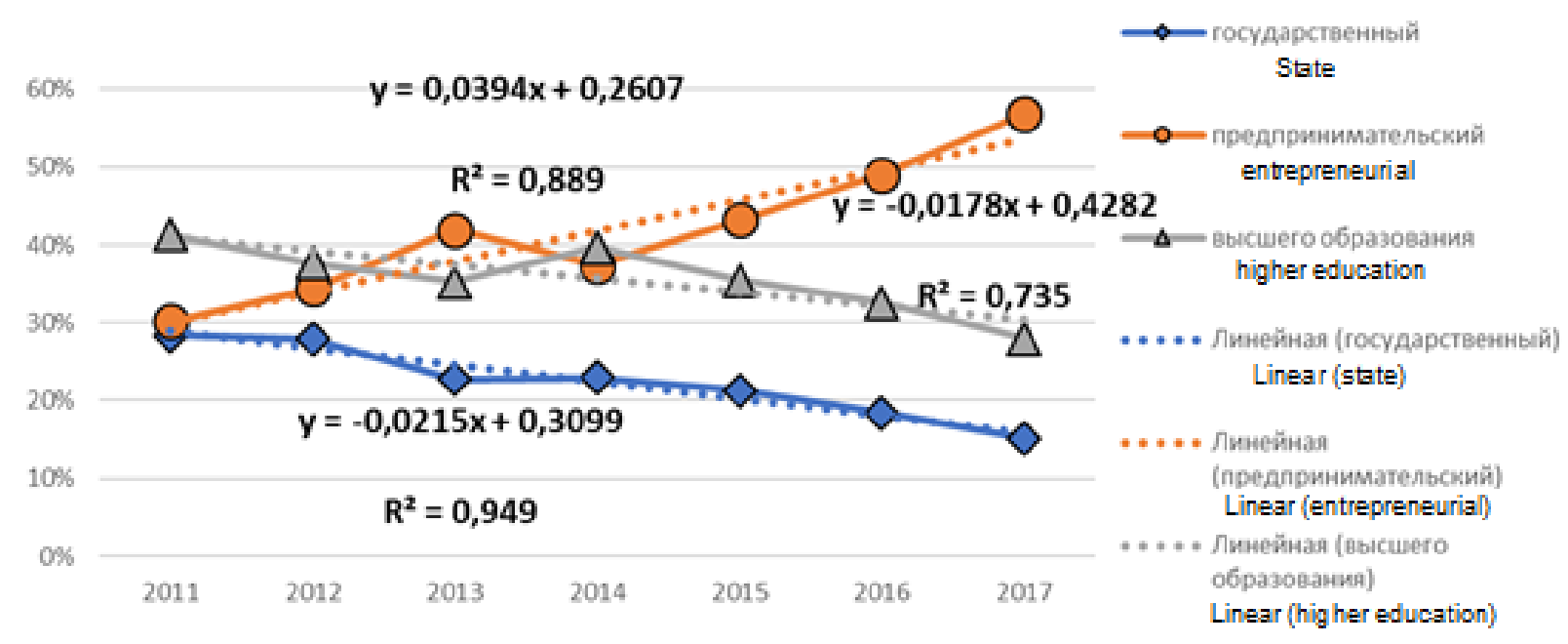

Рис. 6. Доля внутренних затрат на исследования и разработки по секторам деятельности. Томская область (2011-2017)

Fig. 6. Share of internal research and development expenditure by sector of activity. Tomsk region (2011-2017)

Для дополнительной проверки правильности использования индикатора «Доля внутренних затрат на исследования и разработки» для построения регрессионных зависимостей были взяты два индикатора, имеющих близкий экономический смысл из других источников информации. Первый - это «Удельный вес внебюджетных средств во внутренних затратах на исследования и разработки» (Росстат $[9,10])$. Второй - «Доля предпринимательского сектора в научных исследованиях и разработках» (ведомственная отчетность Минобрнауки [12]) (рис. 7). 
Линейная регрессия для индикатора «Удельный вес внебюджетных средств во внутренних затратах на исследования и разработки» имеет вид

$$
\mathrm{y}=-\mathbf{0 , 0 2 9 4 x}+0,4671 ; R^{2}=0,8328 \text {. }
$$

Линейная регрессия для индикатора «Доля предпринимательского сектора в научных исследованиях и разработках» имеет вид

$$
y=-0,0387 x+0,519 ; R^{2}=0,9505 \text {. }
$$

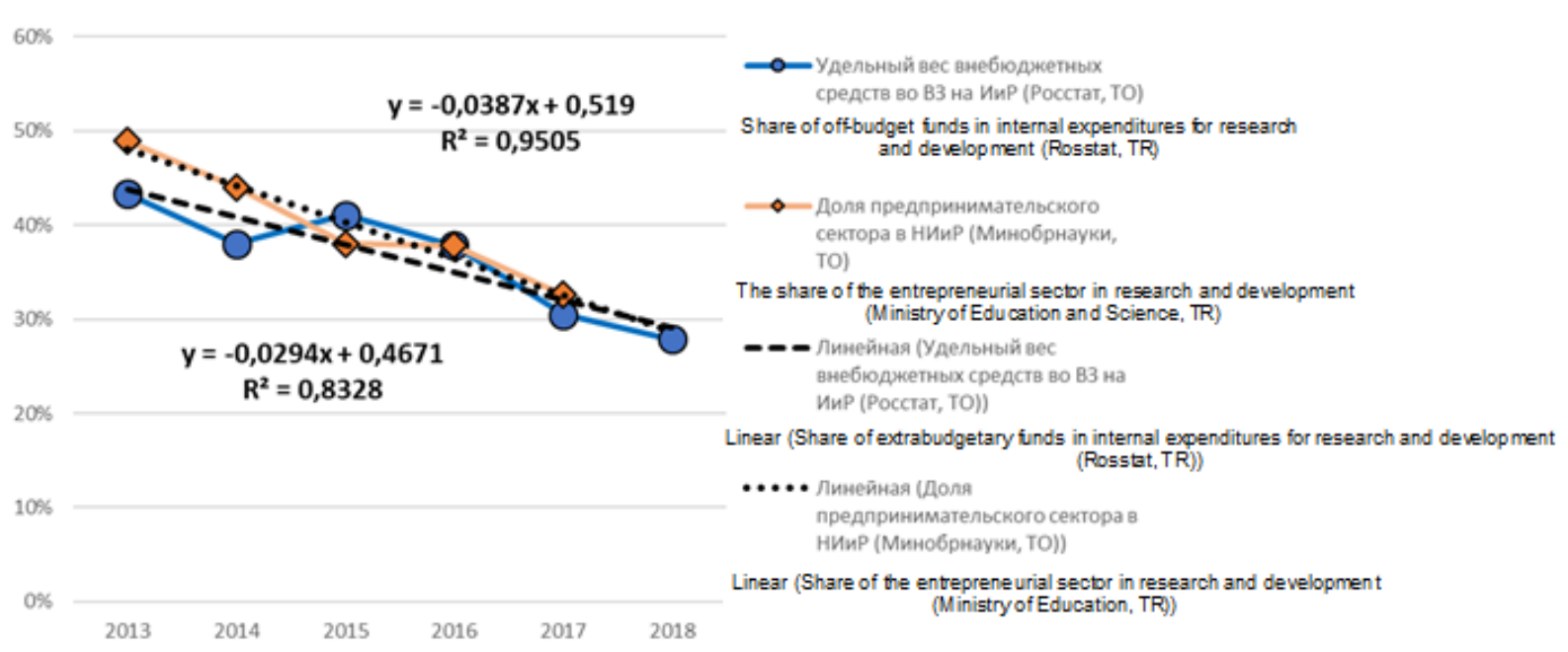

Puc. 7. Удельный вес внебюджетных средств во внутренних затратах на исследования и разработки. Томская область (2013-2018)

Fig. 7. Share of extra-budgetary resources in the internal costs of research and development. Tomsk region (2013-2018)

Близость значений индикаторов и регрессионных зависимостей говорит о том, что внебюджетные средства во внутренних затратах на исследования и разработки в Томской области формируются во многом за счет заказов предпринимательского сектора научных исследований и разработок в университетах и научно-исследовательских институтах Минобрнауки. Степень статистической достоверности говорит о том, что индикатор «Доля внутренних затрат на исследования и разработки» может быть использован для построения математических моделей.

Однако одних статистических данных недостаточно для формулирования (разработки, конструирования) факторов, влияющих на процессы развития и интеграции научно-исследовательских институтов, университетов и высокотехнологичных предприятий в рамках научно-образовательного кластера Томской области.

\section{3. Внутренние (слабости) и внещние (угрозы) проблемы, ограничивающие про-} цессы развития экономики (реализации инновационного потенциала) Томской области, 20112.

В 2011 г. авторами этой статьи был проведен SWOT-анализ развития инновационного потенциала Томской области. В статье [8] приведены результаты этой работы. Состав экспертов формировался по трем группам («Власть», «Наука», «Бизнес») в количестве 37 человек. Проведены ранжирование и оценка взаимного влияния факторов по группам экспертов. Получена общая экспертная оценка и сформирован базовый профиль инновационной стратегии региона.

Воспользуемся результатами этой работы и сравним утверждения экспертов 2011 г. о «слабостях» и «угрозах» развитию региональной инновационной системы с 
факторами, выявленными в результате анализа данных статистики и экспертных оценок 2019 г. При этом будем учитывать, что экономическая ситуация 2011 г. была более благоприятна (подъем экономики).

I. Основной фактор. Рост государственного финансирования прикладных научных исследований в рамках федеральных целевых программ в интересах государственных корпораций (Роскосмос, Ростех, Росатом и т. п.).

II. Основной фактор. Непрерывная реформа Российской академии наук, сопровождающаяся снижением государственного финансирования и заказов со стороны хозяйствующих субъектов.

III. Основной фактор. Непрерывная реформа системы образования и университетов, сопровождающаяся снижением государственного финансирования и заказов со стороны хозяйствующих субъектов.

Значимые утверждения экспертов 2011 г. «Развал системы высшего инженерного и профобразования. Падение квалификации и престижа по многим инженерным и рабочим специальностям».

Парадоксально, но после ранжирования и выделения наиболее значимых утверждений только одно из них рассматривало реформу высшего образования как угрозу. Ни доминирование государственного финансирования прикладных научных исследований, ни реформу РАН эксперты в 2011 г. не считали значимой проблемой. Хотя в исходных 377 утверждениях подобные формулировки встречались.

$I V$. Основной фактор. «Качество государственного управления и регулирования научных исследований».

Значимые утверждения экспертов 2011 г. «Отсутствие федерального законодательства по промышленной и инновационной политике».

«Отсутствие законодательной базы и длинных денег для финансирования долгосрочных инновационных проектов, реализуемых бизнесом».

«Отсутствие экономических стимулов для развития инновационной деятельности (система налогообложения, банковская система, таможенное законодательство)».

«Ф3 № 94 о госзакупках - значительное препятствие продвижению инновационной продукции российских предприятий на рынки РФ».

«Отсутствие системы государственного заказа на отечественные инновационные разработки».

«Отсутствие региональных программ формирования и развития продуктовых направлений (товаров, продуктов, технологий) на основе собственных НТР (в т. ч. кластеров)».

$V$. Основной фактор. «Качество подготовки специалистов».

«Падение образовательных и инженерных (конструкторско-технологических) компетенций по металлообработке и электромеханике».

«Слабая материальная база вузов по подготовке инженеров конструкторскотехнологического профиля».

Остальные значимые утверждения экспертов 2011 г. концентрировались вокруг развития социальной, инженерной, финансовой, инновационной инфраструктуры и взаимосвязей внутри инновационной системы региона.

Вот некоторые из них:

«Разрыв в преемственности компетенций по многим инженерным и рабочим специальностям (возрастной разрыв поколений)».

«Падение престижности инженерных и рабочих профессий».

«Слабо развитые институты защиты интеллектуальной собственности». 
«Усиливающееся отставание общего научно-технологического уровня разработок и бизнеса от мирового уровня».

«Недостаточный уровень развития социальной инфраструктуры. Отсутствие бытовых условий (доступного жилья, детских садов и др.) для молодых ученых, специалистов, инноваторов».

«Слабая финансовая инфраструктура поддержки инновационных проектов и бизнеса (банковское проектное финансирование, венчурное финансирование и др.)».

«Недостаточное развитие инфраструктуры коммерциализации разработок. Системы продвижения и коммерциализации НТР не сформированы».

«Слабая связь организаций НОК с региональным промышленным сектором в плане внедрения завершенных научных разработок».

\section{4. Анализ внутренних и внещних проблем, ограничивающих процессы разви-} тия и препятствующих эффективному взаимодействию организаций кластера. Выделение и формулирование основных факторов, влияющих на процессы развития (2019).

Перечень проблем формируется на основе анализа интервью с экспертами научно-образовательного кластера Томской области.

Методологический подход, изложенный в докладе [14], опирается на систему показателей Российской кластерной обсерватории [15] и предполагает использование экспертного интервью. Оно включает разделы, посвященные (1) сотрудничеству организаций НОК ТО в совместных проектах НИОКР, образовательных и инновационных проектах; (2) характеристике совместных результатов научной деятельности и доходов от интеллектуальной собственности; (3) созданию малых и микропредприятий с участием разных организаций НОК; (4) сотрудничеству участников кластера с крупным бизнесом и властью; (5) развитию системы координации и управления научнообразовательным кластером [14].

Эксперты, непосредственно участвовавшие в подготовке и реализации совместных (наука-бизнес) научно-исследовательских и опытно-конструкторских проектов и дававшие интервью, в количестве 12 человек были отобраны из числа специалистов научно-исследовательских институтов (4 человека), университетов (5) и крупных высокотехнологичных предприятий региона (3).

В результате анализа проведенных интервью были выделены 102 значащих (обоснованных) утверждения, характеризующих внутренние и внешние проблемы, ограничивающие процессы развития и препятствующие эффективному взаимодействию организаций кластера.

Экспертные семинары с участием 6 человек, имеющих опыт разработки стратегий развития регионов, университетов и высокотехнологичных предприятий, проводились трижды. Первый - при подготовке анкеты полуструктурированного интервью. Второй при выделении значащих утверждений. Третий - при формулировании факторов, влияющих на процессы развития и интеграции научно-исследовательских институтов, университетов и высокотехнологичных предприятий в рамках научно-образовательного кластера Томской области.

Мнения экспертов (интервью 2019 г.) сформировались на основе опыта 2012-2019 гг. Экономический фон, влияющий на формирование этих мнений, отражен в статистических моделях, характеризующих процессы развития научно-образовательного кластера Томской области и приведенных выше.

Дальнейшее изложение результатов анализа строится следующим образом: 
1. Формулирование подтвержденного статистикой факта изменений на протяжении исследуемого периода.

2. Формулирование (разработка, конструирование) основного фактора, влияющего на процесс изменений.

3. Выделение значимых (обоснованных) утверждений экспертов, подтверждающих правильность основного фактора.

Установленный факт. Рост в 2011-2017 гг. доли предпринимательского сектора во внутренних затратах на исследования и разработки (рис. 6).

Линейная регрессия имеет вид

$$
\mathbf{y}=\mathbf{0 , 0 3 9 4 x}+0,2607 ; R^{2}=0,8891 \text {. }
$$

I. Основной фактор. «Рост государственного финансирования прикладных научных исследований в рамках федеральных целевых программ в интересах государственных корпораций (Роскосмос, Ростех, Росатом и т. п.)».

Значимые утверждения экспертов. «Источник денег, чем дальше, тем больше остается один. Это деньги государства» (ФЦП).

«Активное научно-техническое взаимодействие «университет-бизнес» реализуется только в рамках проектов по промышленному партнерству, инициированных государством».

«Большая часть гражданской продукции, выпускаемой предприятием, не имеет направлений для дальнейшего роста, быстро морально устаревает или рассчитана на рынки со снижающимся спросом».

Установленный факт. Снижение в 2011-2017 гг. доли государственного сектора во внутренних затратах на исследования и разработки (рис. 6).

Линейная регрессия имеет вид

$$
\mathbf{y}=-0,0215 x+0,3099 ; R^{2}=0,9493 .
$$

II. Основной фактор. «Непрерывная реформа Российской академии наук, сопровождающаяся снижением государственного финансирования и заказов со стороны хозяйствующих субъектов».

Значимые утверждения экспертов. «ФАНО, а затем Министерство науки и высшего образования РФ лишили РАН многих функций управления, но не взяли их на себя. Нет системы взаимодействия научно-исследовательских институтов с Министерством».

«Грантовое финансирование на ограниченный срок 2-3 года не позволяет сосредоточиться на работах, требующих 5-6-летнего непрерывного финансирования».

«Разрушена система обмена информацией с бизнесом, нет регулярных встреч, совместных семинаров и т. п.».

«Значительное отставание от мирового уровня по многим направлениям научных исследований. Технологическое отставание от ведущих зарубежных стран мира».

«Отсутствие у предприятий долгосрочного планирования продуктового портфеля и прикладных исследований, финансирование предприятиями НИОКР осуществляется в основном только по конкретным проектам».

Установленный факт. Снижение в 2011-2017 гг. доли сектора высшего образования во внутренних затратах на исследования и разработки (рис. 6).

Линейная регрессия имеет вид

$$
\mathbf{y}=-\mathbf{0 , 0 1 7 8 x}+\mathbf{0 , 4 2 8 2} ; \mathbf{R}^{\mathbf{2}}=\mathbf{0 , 7 3 5 3}
$$

III. Основной фактор. «Непрерывная реформа системы образования и университетов, сопровождающаяся снижением государственного финансирования и заказов со стороны хозяйствующих субъектов». 
Значимые утверждения экспертов. «Частое реформирование системы образования и университетов, участвующих в кооперации, которое приводит к нарушению установившихся связей».

«Увеличивающийся разрыв в инжиниринговых и проектно-технологических компетенциях Университета от требований предприятий».

«Инициативных работ нет из-за отсутствия ресурсов у предприятия и системы показателей отчетности университета».

Необходимо отметить, что снижение доли внутренних затрат на исследования и разработки и реформы государственного сектора (РАН) и сектора высшего образования (университеты) приводят к практически полному совпадению заключений экспертов из университетов и НИИ. Тем более, что эти реформы проходят в рамках одной госструктуры - Минобрнауки РФ и, очевидно, имеют общую цель.

Однако выявленные на основании анализа статистических зависимостей факторы касаются лишь трети значимых утверждений экспертов. Анализ оставшейся группы индикаторов позволяет выявить по крайней мере еще два фактора, влияющих на процессы развития и препятствующих эффективному взаимодействию организаций кластера. Это «Качество государственного управления и регулирования научных исследований» и «Качество подготовки специалистов». К сожалению, доступные данные статистики и ведомственной отчетности не позволяют перевести эти факторы в измеряемые показатели.

$I V$. Основной фактор. «Качество государственного управления и регулирования научными исследованиями»

Значимые утверждения экспертов. «Система госбюджетного финансирования (сдвиг сроков финансирования относительно графика выполнения проекта) не обеспечивает выполнение требований технического задания и качества проведения НИОКР».

«Индексы Минэкономразвития РФ не соответствуют инфляции, в связи с чем необходимое технологическое оборудование невозможно закупить без превышения сметной стоимости».

«Сложившаяся система распределения контрактов среди аффилированных с госструктурами компаний исключает конкуренцию и снижает научный уровень разработок».

«С региональной властью взаимодействие осталось на уровне подготовки проектов, написания бумаг практически без осязаемого результата».

$V$. Основной фактор. «Качество подготовки специалистов».

Значимые утверждения экспертов. «Сокращение таких дисциплин, как конструирование, машино- и приборостроение, электроника приводит к низкому качеству знаний студентов по направлениям, представляющим интерес для предприятия».

«Слабая инжиниринговая, технологическая подготовка молодых специалистов для решения проектно-технологических задач по разработке и запуску изделия в производство».

«Специалисты предприятий в своем большинстве не готовы к участию в учебном процессе в университете и не заинтересованы к работе со студентом во время производственных практик».

«Дефицит высококвалифицированных кадров со средним и высшим профессиональным образованием. Диспропорция между квалификацией персонала и требованиями работодателей к исполнителям НИОКР».

Приведем еще несколько значимых утверждений экспертов, указывающих, что перечень основных факторов далеко не полон. 
«Критический разрыв в отдельных компетенциях у разработчиков проектов разных возрастных поколений».

«Высокий уровень зависимости при проведении НИОКР от импортной компонентной базы (по отдельным направлениям)».

«Оформление патентов и регистрация результатов интеллектуальной деятельности не является значимой для разработчиков НИОКР, если это не является требованием проекта (в связи с коротким сроком реализации проектов и большими затратами времени и денег)».

«Оформление результатов НИОКР в виде диссертаций не является значимой и приоритетной для большинства разработчиков».

«Деятельность организаций инновационной инфраструктуры сворачивается».

«Существующий кластер - формальная структура, клуб по интересам, не оказывающий какого-либо влияния на проектно-исследовательскую деятельность его участников. Формализованный кластер не заинтересован во взаимодействии с наукой».

«Нет заинтересованности в работе с малыми предприятиями».

«Отсутствие заказов от бизнеса и госстуктур приводит высокотехнологичный малый бизнес к борьбе за выживание».

«Нарушены научные связи НИИ с университетами, научное общение».

\section{Обсуждение и выводы}

В работе представлена модель-видение взаимодействия основных элементов научно-образовательного регионального кластера. Подчеркнуто, что каждый из элементов является частью вертикально интегрированных структур. Организации высшего образования входят с систему Минобрнауки РФ, научные организации - в системы Минобрнауки РФ и РАН, крупные и средние высокотехнологичные предприятия - в системы госкорпораций и естественных монополий или тесно сотрудничают с ними. Государство, с одной стороны, задает «правила игры» и обеспечивает текущее функционирование организаций, с другой - стимулирует взаимодействие науки и бизнеса. Одновременно выделенные элементы являются частью национальной и региональной инновационных систем. Сетевые взаимодействия формируются на основе технологических цепочек (производственная кооперация) и рыночного взаимодействия.

Разработаны статистические модели, характеризующие процессы развития научно-образовательного кластера Томской области.

Данные по динамике производства показывают несколько периодов развития: значительный рост 2005-2007 гг., кризис 2008-2009 гг., послекризисный подъем 2010-2012 гг., стагнацию и неустойчивый рост 2013-2018 гг. Динамика производства по ВЭД «Научные исследования и разработки» несколько другая. Колебания показателей «сдвинуты» примерно на два года. Понимание динамики изменений необходимо для корректной интерпретации экспертных мнений, т. к. они формируются примерно за 5-7-летний период.

Рассмотрено финансирование науки в университетах и научно-исследовательских институтах Томской области по данным региональной и ведомственной отчетности (2014-2018).

Приведенная информация показывает, что для университетов большое значение имеют средства, поступающие из внебюджетных источников (от 47 до $52 \%$ от общего финансирования науки за указанный период) и в рамках ФЦП «Исследования и разработки» и ПП № 218 (до 40 от общего финансирования науки в 2017 г.). Но эти источники показывают тенденцию к уменьшению. 
Сложная ситуация с финансированием науки складывается в научноисследовательских институтах региона. Кратное сокращение бюджетного финансирования (в 2,5 раза в 2014, 2015 гг.) сопровождалось значительным падением финансирования из внебюджетных источников. Причем в 2016 г. оно уменьшилось по сравнению с 2014 г. в 5 раз. Формирующийся источник ФЦП «Исследования и разработки» не компенсирует этого падения.

В целом по НОК ТО можно говорить о сформировавшейся в 2014-2018 гг. тенденции сокращения финансирования из всех источников. Объем договоров с российскими хозяйствующими субъектами сокращается, бюджетная поддержка тоже не увеличивается, новых значимых источников финансирования на обозримую перспективу нет.

В работе рассмотрены внутренние затраты на исследования и разработки по секторам деятельности в динамике за 2011-2017 гг. Построены регрессионные зависимости для государственного, предпринимательского секторов и сектора высшего образования. Степень статистической достоверности (значение параметра $\mathrm{R}^{2}$ ) достаточна, чтобы сформулировать гипотезу, что в каждой зависимости проявляется долгосрочный значительный фактор, воздействующий на процессы на протяжении исследуемого периода времени.

Анализ динамики удельного веса внебюджетных средств во внутренних затратах на исследования и разработки показал, что внебюджетные средства во внутренних затратах на исследования и разработки в Томской области формируются во многом за счет заказов предпринимательского сектора научных исследований и разработок в университетах и научно-исследовательских институтах Минобрнауки.

На основе анализа экспертных мнений (2019) о внутренних и внешних проблемах, ограничивающих процессы развития и препятствующих эффективному взаимодействию организаций кластера, выделены основные факторы, влияющие на исследуемые процессы.

Три из них подтверждены данными статистики, найденными математическими зависимостями и экспертными мнениями. Это «Рост государственного финансирования прикладных научных исследований в рамках федеральных целевых программ в интересах государственных корпораций (Роскосмос, Ростех, Росатом и т. п.)», «Непрерывная реформа Российской академии наук, сопровождающаяся снижением государственного финансирования и заказов со стороны хозяйствующих субъектов», «Непрерывная реформа системы образования и университетов, сопровождающаяся снижением государственного финансирования и заказов со стороны хозяйствующих субъектов». Еще два фактора сформулированы в результате обобщения экспертных мнений. Это «Качество государственного управления и регулирования научными исследованиями», «Качество подготовки специалистов».

На основе анализа экспертных мнений (2011) исследованы внутренние и внешние проблемы (слабости и угрозы), ограничивающие процессы развития экономики (реализации инновационного потенциала) Томской области. Наиболее значимые утверждения соотнесены с выделенными в 2019 г. основными факторами. Парадоксально, но после ранжирования и выделения наиболее значимых утверждений только одно из них рассматривало реформу высшего образования как угрозу. Ни доминирование государственного финансирования прикладных научных исследований в предпринимательском секторе, ни реформу РАН эксперты в 2011 г. не считали значимыми проблемами. Хотя в исходных 377 утверждениях подобные формулировки встречались.

Преемственность мнений экспертов в 2011 и 2019 гг. наблюдалась при оценке факторов «Качество государственного управления и регулирования научными исследованиями» и «Качество подготовки специалистов». 
Говоря о сопоставлении экспертных мнений 2011 и 2019 гг. в целом, необходимо подчеркнуть гораздо более жёсткое и критическое отношение специалистов в 2019 г. к внутренним и внешним проблемам экономики Томской области и России, ограничивающим процессы развития и препятствующим эффективному взаимодействию организаций кластера.

Общий вывод. Динамика изменений статистических показателей и экспертных оценок проблем развития научно-образовательного кластера Томской области в 2011-2019 гг. показывает значительное ухудшение экономической ситуации в стране и нарастание критического отношения специалистов к разработке и реализации политики поддержки научно-технологического развития России.

Исследование выполнено при финансовой поддержке РФФИ в рамках научно- исследовательского проекта «Исследование процессов интеграции научно-исследовательских институтов, университетов и высокотехнологичных предприятий на примере научно-образовательного кластера Томской области», проект № 18-010-00917a.

\section{СПИСОК ЛИТЕРАТУРЫ}

1. United Nations Industrial Development Organization, 2015. Industrial Development Report 2016. The Role of Technology and Innovation in Inclusive and Sustainable Industrial Development. Vienna. URL: https://www.unido.org/fileadmin/user_media_upgrade/Resources/Publications/EBOOK_IDR2016_FULLR EPORT.pdf (дата обращения 24.09.2019).

2. High-tech industry and knowledge-intensive services. - Eurostat. URL: https://ec.europa.eu/eurostat/cache/ metadata/en/htec_esms.htm (дата обращения 24.09.2019).

3. Research and innovation statistics at regional level. Eurostat regional yearbook. URL: https://ec.europa.eu/ eurostat/statistics-explained/index.php?title=Research_and_innovation_statistics_at_regional_level (дата обращения 24.09.2019).

4. Акофф Р. Планирование будущего корпорации. - М.: Прогресс, 1985. - 327 с.

5. Клейнер Г.Б. «Мягкие» и «жесткие» системы в экономике // XVII Международная конференция по мягким вычислениям и измерениям. Круглый стол «Экономическая кибернетика и мягкая системная экономика». - СПб.: СПбГЭТУ «ЛЭТИ», 2014. - С. 6-12.

6. Зуб А.Т., Локтионов М.В. Стратегический менеджмент: Системный подход. - М.: Генезис, 2011. - 848 с.

7. Гуменников И.В., Монастырный Е.А. Комплексное моделирование социально-экономических процессов и систем. Мягкий системный анализ // Информационные технологии в науке, управлении, социальной сфере и медицине: сборник научных трудов $\mathrm{V}$ Международной научной конференции. Часть 2. - Томск: Изд-во ТПУ, 2018. - С. 437-443.

8. Губин Е.П., Монастырный Е.А., Пушкаренко А.Б. Исследование основных тенденций развития инновационной системы Томской области. SWOT-анализ // Инновации. - 2012. - № 8 (166). - С. 71-79.

9. Федеральная служба государственной статистики России. URL: https://www.gks.ru/ (дата обращения 21.02.2020).

10. Единая межведомственная информационно-статистическая система. URL: https://fedstat.ru/ (дата обращения 21.02.2020).

11. Территориальный орган Федеральной службы государственной статистики по Томской области. URL: https://tmsk.gks.ru/ (дата обращения: 21.02.2020).

12. Научный потенциал вузов Сибирского федерального округа. 2017 / под ред. В.М. Кутузова. - СПб.: СПбГЭТУ, 2018. - 234 с.

13. Основные результаты деятельности научно-образовательного комплекса Томской области в 2018 году. - Департамент науки и высшего образования администрации Томской области. - Томск, 2019. - 68 c. URL: file://fs.copp.local/docs_pers\$/EVGiniyatova/Downloads/\%D0\%9E\%D1\%81\%D0\% BD\%D0\%BE\%D0\%B2\%D0\%BD\%D1\%8B\%D0\%B5\%20\%D1\%80\%D0\%B5\%D0\%B7\%D1\%83\%D0\%BB\% D1\%8C\%D1\%82\%D0\%B0\%D1\%82\%D1\%8B\%20\%D0\%B4\%D0\%B5\%D1\%8F\%D1\%82\%D0\%B5\%D0\%B B\%D1\%8C\%D0\%BD\%D0\%BE\%D1\%81\%D1\%82\%D0\%B8\%20\%D0\%BD\%D0\%B0\%D1\%83\%D1\%87\%D 0\%BD\%D0\%BE-\%D0\%BE\%D0\%B1\%D1\%80\%D0\%B0\%D0\%B7\%D0\%BE\%D0\%B2\%D0\% B0\%D1\%82\% D0\%B5\%D0\%BB\%D1\%8C\%D0\%BD\%D0\%BE\%D0\%B3\%D0\%BE\%20\%D0\%BA\%D0\%BE\%D0\%BC\%D0 $\% \mathrm{BF} \% \mathrm{D} 0 \% \mathrm{BB} \% \mathrm{D} 0 \% \mathrm{~B} 5 \% \mathrm{D} 0 \% \mathrm{BA} \% \mathrm{D} 1 \% 81 \% \mathrm{D} 0 \% \mathrm{~B} 0 \% 20 \% \mathrm{D} 0 \% \mathrm{~A} 2 \% \mathrm{D} 0 \% \mathrm{BE} \% \mathrm{D} 0 \% \mathrm{BC} \% \mathrm{D} 1 \% 81 \% \mathrm{D} 0 \% \mathrm{~B}$ A\%D0\%BE\%D0\%B9\%20\%D0\%BE\%D0\%B1\%D0\%BB\%D0\%B0\%D1\%81\%D1\%82\%D0\%B8\%20\%D0\%B 2\%202017\%20\%D0\%B3\%D0\%BE\%D0\%B4\%D1\%83.pdf (дата обращения 21.02.2020). 
14. Павлова И.А. Особенности участия научно-исследовательских институтов в интеграционных процессах в научно-образовательном кластере Томской области // Рост производительности труда - решающее условие экономического прорыва. - Новосибирск: НГТУ, 2019. - С. 31-39.

15. Методологические рекомендации по реализации кластерной политики в субъектах Российской Федерации // Министерство экономического развития Российской Федерации. URL: http://economy. gov.ru/minec/activity/sections/innovations/development/doc1248781537747 (дата обращения 01.11.2019).

Поступила 22.02.2020 г. 


\title{
PROBLEMS OF DEVELOPMENT OF SCIENTIFIC AND EDUCATIONAL CLUSTER OF THE TOMSK REGION IN 2011-2019: DYNAMICS OF CHANGES OF STATISTICAL INDICATORS AND EXPERT ESTIMATES
}

\author{
Evgeny P. Gubin1, \\ evgenii.p.gubin@tusur.ru \\ Eugeniy A. Monastyrny 2,1,3, \\ e.monastyrny@gmail.com
1 Tomsk State University of Control Systems and Radioelectronics, 40, Lenin avenue, Tomsk, 634050, Russia.
2 National Research Tomsk Polytechnic University, 30, Lenin avenue, Tomsk, 634050, Russia.
3 Tomsk Scientific Center SB RAS, 10/4, Academichesky avenue, Tomsk, 634055, Russia.

Evgeny P. Gubin, associate professor, Tomsk State University of Control Systems and Radioelectronics.

Eugeniy A. Monastyrny, Dr. Sc., professor, National Research Tomsk Polytechnic University; professor, Tomsk State University of Control Systems and Radioelectronics; head of the laboratory of sustainability of socio-economic systems, Tomsk Scientific Center SB RAS.

Relevance. Formation of competitive territories and regions is one of the priority tasks of the state policy of the Russian Federation, within the framework of which there is an acute issue of assessing the types of economic activities that can become drivers of innovative and socio-economic development of regions. The aim of the study is to compare the dynamics of changes in activity objective statistical indicators and subjective expert assessments of the problems of scientific and educational cluster development in the Tomsk region. The sources of information are Rosstat, Unified Interagency Statistical Information System (EMISS), Tomskstat, departmental and regional reporting, expert estimates. Methodology. To analyze quantitative data, the authors use the approaches of descriptive statistics: comparisons, relations, visualization of change dynamics, statistical analysis; regression analysis. To analyze qualitative data the authors apply the methods of selection of factors characterizing external and internal problems (threats and weaknesses) of the processes under study from expert opinions. Results. The authors have developed the model-vision of interaction of the main elements of scientific and educational regional cluster, statistical models characterizing the development of scientific and educational cluster of the Tomsk region. The paper considers the financing of science in universities and research institutes of the Tomsk region according to regional and departmental reporting (2014-2018). Based on NOC of Tomsk region it is possible to speak about a tendency of reduction of financing from all sources formed in 2014-2018. The volume of contracts with Russian business entities is decreasing, budget support is not increasing either, there are no new significant sources of financing for the foreseeable future. The article deals with internal costs of research and development by sectors of activity in the dynamics for 2011-2017. Regression dependencies are built for state, entrepreneurial and higher education sectors. The degree of statistical reliability (value of parameter $R^{2}$ ) is sufficient to formulate a hypothesis that in each of the dependencies there is a long-term significant factor affecting the processes during the time period under study. Based on the analysis of expert opinions (2019) on internal and external problems that limit the development and prevent effective interaction of the cluster organizations, the main factors affecting the processes under study are identified. These are «Growth of Public Funding for Applied Research within the Framework of Federal Targeted Programs in the Interests of State Corporations (Roskosmos, Rostekh, Rosatom, etc.)》, "Continuous Reform of the Russian Academy of Sciences accompanied by a Decline in Public 
Funding and Orders from Business Entities», "Continuous Reform of the Education System and Universities accompanied by a Decrease in Public Funding and Orders from Business Entities», "Quality of Public Administration». Speaking about the comparison of expert opinions in 2011 and 2019 in general, it is necessary to emphasize a much tougher and more critical attitude of specialists in 2019 to the internal and external problems of the economy of the Tomsk region and Russia, which limits the development and prevents effective interaction of the cluster organizations. General conclusion. The dynamics of changes in statistical indicators and expert assessments of the problems of development of scientific and educational cluster of the Tomsk region in 2011-2019 shows a significant deterioration of the economic situation in the country and the growing critical attitude of specialists to development and implementation of policies to support the scientific and technological development of Russia.

Key words: High-tech enterprises, universities, research institutes, applied science, scientific and educational cluster, statistics, expert assessments, modeling, regression analysis, Tomsk region.

The research was financially supported by the RFBR within the science and research project «Study of integration of research institutes, universities and high-tech enterprises on the example of scientific and educational cluster of Tomsk region», project no. 18-010-00917a.

\section{REFERENCES}

1. United Nations Industrial Development Organization, 2015. Industrial Development Report 2016. The Role of Technology and Innovation in Inclusive and Sustainable Industrial Development. Vienna. Available at: https://www.unido.org/fileadmin/user_media_upgrade/Resources/Publications/EBOOK_IDR2016_FULLR EPORT.pdf (accessed 24 September 2019).

2. High-tech industry and knowledge-intensive services. Eurostat. Available at: https://ec.europa.eu/eurostat/ cache/metadata/en/htec_esms.htm (accessed: 24 September 2019).

3. Research and innovation statistics at regional level. Eurostat regional yearbook. Available at: https://ec.europa.eu/eurostat/statistics-

explained/index.php?title=Research_and_innovation_statistics_at_regional_level (accessed: 24 September 2019).

4. Akoff R. Planirovanie budushchego korporatsii [Planning the future of the corporation]. Moscow, Progress Publ., 985. 327 p.

5. Kleyner G.B. «Myagkie» i «zhestkie» sistemy v ekonomike [«Soft» and «hard» systems in economics]. XVII Mezhdunarodnaya konferentsiya po myagkim vychisleniyam i izmereniyam. Krugly stol «Ekonomicheskaya kibernetika i myagkaya sistemnaya ekonomika» [XVII International Conference on Soft Computing and Measurements. Round table «Economic cybernetics and soft systems economy»]. St. Petersburg, SPbGETU «LETI» Publ., 2014. pp. 6-12.

6. Zub A.T., Loktionov M.V. Strategicheskiy menedzhment: sistemny podkhod [Strategic management: a systematic approach]. Moscow, Genezis Publ., 2011. 848 p.

7. Gumennikov I.V., Monastyrny E.A. Kompleksnoe modelirovanie sotsialno-ekonomicheskikh protsessov i sistem. Myagkiy sistemny analiz [Integrated modeling of socio-economic processes and systems. Soft system analysis]. Informatsionnye tekhnologii $v$ nauke, upravlenii, sotsialnoy sfere $i$ meditsine: sbornik nauchnykh trudov V Mezhdunarodnoy nauchnoy konferentsii. Chast 2 [Information technologies in science, management, social sphere and medicine: collection of scientific papers of the $\mathrm{V}$ International scientific conference. Part 2]. Tomsk, TPU Publ., 2018. pp. 437-443.

8. Gubin E.P., Monastyrniy E.A., Pushkarenko A.B. The study of major developments in the innovation system of the Tomsk region. SWOT analysis. Innovation, 2012, no. 8 (166), pp. 71-79.

9. Federalnaya sluzhba gosudarstvennoy statistiki Rossii [Federal State Statistics Service of Russia]. Available at: https://www.gks.ru/ (accessed 21 February 2020).

10. Edinaya mezhvedomstvennaya informatsionno-statisticheskaya sistema [Unified interdepartmental information and statistical system]. Available at: https://fedstat.ru/ (accessed 21 February 2020).

11. Territorialny organ Federalnoy sluzhby gosudarstvennoy statistiki po Tomskoy oblasti [Territorial body of the Federal State Statistics Service in the Tomsk Region]. Available at: https://tmsk.gks.ru/ (accessed 21 February 2020).

12. Nauchny potentsial vuzov Sibirskogo federalnogo okruga. 2017 [Scientific potential of universities of the Siberian Federal District. 2017]. Ed. by V.M. Kutuzov. St. Petersburg, SPbGETU Publ., 2018. 234 p. 
13. Osnovnye rezultaty deyatelnosti nauchno-obrazovatelnogo kompleksa Tomskoy oblasti v 2018 godu [The main results of the activities of the scientific and educational complex of the Tomsk region in 2018]. Departament nauki $i$ vysshego obrazovaniya administratsii Tomskoy oblasti [Department of Science and Higher Education of the Administration of the Tomsk Region]. Tomsk, 2019. 68 p. Available at: file://fs.copp.local/docs_pers\$/EVGiniyatova/Downloads/\%D0\%9E\%D1\%81\%D0\%BD\%D0\%BE\%D0\%B 2\%D0\%BD\%D1\%8B\%D0\%B5\%20\%D1\%80\%D0\%B5\%D0\%B7\%D1\%83\%D0\%BB\%D1\%8C\%D1\%82 \%D0\%B0\%D1\%82\%D1\%8B\%20\%D0\%B4\%D0\%B5\%D1\%8F\%D1\%82\%D0\%B5\%D0\%BB\%D1\%8C\% D0\%BD\%D0\%BE\%D1\%81\%D1\%82\%D0\%B8\%20\%D0\%BD\%D0\%B0\%D1\%83\%D1\%87\%D0\%BD\%D 0\%BE-\%D0\%BE\%D0\%B1\%D1\%80\%D0\%B0\%D0\%B7\%D0\%BE\%D0\%B2\%D0\%B0\%D1\%82\%D0\% B5\%D0\%BB\%D1\%8C\%D0\%BD\%D0\%BE\%D0\%B3\%D0\%BE\%20\%D0\%BA\%D0\%BE\%D0\%BC\%D0\% BF\%D0\%BB\%D0\%B5\%D0\%BA\%D1\%81\%D0\%B0\%20\%D0\%A2\%D0\%BE\%D0\%BC\%D1\%81\%D0\%B A\%D0\%BE\%D0\%B9\%20\%D0\%BE\%D0\%B1\%D0\%BB\%D0\%B0\%D1\%81\%D1\%82\%D0\%B8\%20\%D0 \%B2\%202017\%20\%D0\%B3\%D0\%BE\%D0\%B4\%D1\%83.pdf (accessed 21 February 2020).

14. Pavlova I.A. Osobennosti uchastiya nauchno-issledovatelskikh institutov v integratsionnykh protsessakh $\mathrm{v}$ nauchno-obrazovatelnom klastere Tomskoy oblasti [Features of the participation of research institutes in integration processes in the scientific and educational cluster of the Tomsk region]. Rost proizvoditelnosti truda - reshayushchee uslovie ekonomicheskogo proryva [Labor productivity growth is a decisive condition for an economic breakthrough]. Novosibirsk, NGTU, 2019. pp. 31-39.

15. Metodologicheskie rekomendatsii po realizatsii klasternoy politiki v subektakh Rossiyskoy Federatsii [Methodological recommendations for the implementation of cluster policy in the constituent entities of the Russian Federation]. Available at: http://economy.gov.ru/minec/activity/sections/innovations/development/doc1248781537747 (accessed 1 November 2019).

Received: 22 February 2020. 